\title{
The diagnostic challenge of styloid elongation (Eagle's syndrome)
}

\author{
WILLIAM A. WOOLERY, DO
}

\begin{abstract}
Eagle's syndrome is a relatively common disorder that is frequently misdiagnosed. It occurs more frequently in women. Presenting symptoms generally include posterior oropharyngeal pain, intermittent glossitis, and phantom foreign body discomfort of the pharynx. Surgical removal of elongated styloid processes generally provides relief of symptoms.
\end{abstract}

Eagle originally described two distinct syndromes associated with the anomalous growth of the styloid process of the temporal bone. ${ }^{1-3}$ The classic styloid process syndrome occurs primarily after tonsillectomy. The symptom triad includes the feeling of a foreign body lodged in the throat with associated difficulty in swallowing, posterior oropharyngeal pain with deglutition, and the sensation of a slow-healing ulcer in the throat. Patients may complain of pain when turning the head, vertigo, regional carotodynia, and occasionally tinnitus. The second syndrome will be described in the discussion section.

Eagle's syndrome is reported more frequently in women. Symptoms generally occur after the age of 30 years. Although bilateral styloid elongation occurs more frequently, unilateral symptomatic complaints dominate.

\section{Report of case}

A 72-year-old woman was seen with a 22 -year history of glossopharyngeal neuralgia. Symptoms consisted of left-sided cervical triangle pain radiating to the left ophthalmic region when pain was se-

Dr Woolery is clinical assistant professor, department of family and community medicine, School of Medicine, Mercer University, Macon, Ga.

Reprint requests to William A. Woolery, DO, 205 Dental Dr, Suite 18 \& 19, Warner Robins, GA 31088-6073. vere, and intermittent posterior oropharyngeal pain when swallowing. Previous diagnoses had included glossopharyngeal neuralgia, temporomandibular joint syndrome, glossitis, thyroiditis, and psychosomatic neuralgia.

Intraoral examination revealed bilateral styloid elongation. Palpation of the left posterior tonsillar pillar elicited characteristic pain distribution of the posterior oropharynx. Examination of the neck revealed no abnormalities. Palpation over the left external carotid artery or maximal rotation of the head to the right produced intensified cervical triangle and posterior tongue pain.

Angiographic examination demonstrated normal carotid artery anatomy. Computerized tomography and magnetic resonance imaging of the head and neck revealed no abnormalities. Panoramic radiographic examination of the skull demonstrated bilateral styloid elongation (left $74 \mathrm{~mm}$, right $68 \mathrm{~mm}$ ) and stylohyoid ligament calcification (mineralization).

Pharmacologic treatment with phenytoin sodium (Dilantin), carbamazepine (Tegretol), clonazepam (Klonopin), tocainide hydrochloride (Tonocard), and numerous tricyclic antidepressants has been tried without success. Transpharyngeal injection of a long-acting steroid with $2 \%$ lidocaine (Xylocaine) at one time produced temporary pain relief. $\mathrm{Pa}$ tient reluctance has delayed any surgical attempt as a treatment option.

\section{Discussion}

Marchetti, in 1652, first documented stylohyoid ligament ossification. In 1907, Dwight demonstrated that various types of head and neck pain could be related to anatomic variations of the stylohyoid ligament. Eagle subsequently described two distinct syndromes associated with anomalous growth of the styloid process: the styloid process syndrome (stylohyoid syndrome, styloid process neuralgia) and the carotid artery syndrome (styloid process-carotid artery syndrome). ${ }^{4,5}$ 
Pain associated with the styloid process syndrome may be caused by fibrous connective tissue entrapment involving the fifth, seventh, eighth, ninth, and tenth cranial nerves ${ }^{6,7} \mathrm{Fi}$ brous connective tissue may form as a result of fracture of an ossified stylohyoid ligament, degenerative inflammatory changes in the tendinous portion of the stylohoid ligament insertion (insertion tendinosis), or posttonsillectomy fibrotic changes over an elongated styloid process.

It is theorized that carotodynia originates from impingement of the internal or external carotid artery musculature. Direct vasculature impairment or stimulation (or both) of the arterial sheath sympathetic plexus can result in a wide variety of symptoms. Impairment of the internal carotid artery results in pain distribution throughout the ipsilateral ophthalmic artery and parietal pain. External carotid artery involvement will cause ipsilateral infraorbital pain and temporo-occipital discomfort or both. ${ }^{6-8}$

Eagle's syndrome is the symptomatic elongation of the styloid process of the temporal bone or mineralization of the stylohyoid ligament or both. The feature most pathognomonic of this syndrome is the reproducibility of pain with intraoral palpation of the styloid process. Myriad symptoms may be associated with this syndrome and misdiagnosis is common.

\section{Treatment modes}

Intraoral steroid injections have produced varying results in the treatment of classic styloid process syndrome. Simple intraoral digital fracturing of the styloid process rarely relieves symptoms or pain. ${ }^{9}$

Surgical attempts at removal of an elongated styloid process may be made through extraoral transpharyngeal techniques. The main advantages of the extraoral approach are adequate anatomic exposure of related structures and decreased risk of bacterial contamination. The use of general anesthesia and resulting external skin scarring are major disadvantages of this approach. The intraoral transpharyngeal surgical approach is performed with the patient under local anesthesia, which is the primary advantage of this technique. Risk of deep cervical infection and potential trauma to the external carotid artery or facial nerve are the primary objections to using this technique. ${ }^{10-13}$

\section{Summary}

The case presented here is typical of Eagle's syndrome. The patient had styloid elongation associated with characteristic symptoms, and the syndrome had multiple diagnoses over the years.

1. Eagle WW: Elongated styloid process: Report of two cases: Arch Otolaryngol 1937;25:584-587.

2. Eagle WW: Elongated styloid process: Further observations and a new syndrome. Arch Otolaryngol 1948;47:630-640.

3. Eagle WW: Symptomatic elongated styloid process. Arch Otolaryngol 1949;49:490-503.

4. Baddour HM, McAneur JT, Tilson HB: Eagle's syndrome. Oral Surg Oral Med Oral Pathol 1978;46:489-493.

5. Winkler S, Sammartino FJ Sr, Sammartino FJ Jr, et al: Stylohyoid syndrome. Oral Surg Oral Med Oral Pathol 1981;51:215. 217.

6. Langlais RP, Miles DA, VanDis ML: Elongated and mineralized styloyhyoid ligament complex: A proposed classification and report of a case of Eagle's syndrome. Oral Surg Oral Med Oral Pathol 1986;61:527-532.

7. Keur JJ, Campbell JPS, McCarthy JF, et al: The clinical significance of the elongated styloid process. Oral Surg Oral Med Oral Pathol 1986;61:399-404.

8. Christiansen TA, Meyerhoff WL, Quick CA: Styloid process neuralgia. Arch Otolaryngol 1975;101:120-122.

9. Messer EJ, Abramson AM: The stylohyoid syndrome. J Oral Maxillofac Surg 1975;33:664-667.

10. Strauss M, Zohar Y, Laurian N: Elongated styloid process syndrome: Intraoral versus external approach for styloid surgery. Laryngoscope 1985;95:976-979.

11. Chase DC, Zarmen A, Bigelow WC, et al: Eagle's syndrome: A comparison of intraoral versus extraoral surgical approaches. Oral Surg Oral Med Oral Pathol 1986;62:625-629.

12. Moffat DA, Ramsden RT, Shaw HJ: The styloid process syndrome: Aetological factors and surgical management $J$ Laryngol Otol 1977;91:279-294.

13. Glogoff MR, Baum SM, Chiefetz I: Diagnosis and treatment of Eagle's syndrome. J Oral Maxillofac Surg 1981;39:941 -944. 